\title{
Caracterização Mecânica de Compósitos Cimentícios Reforçados com Fibras de Politereftalato de Etileno Espiraladas
}

\section{Mechanical Characterization of Cementitious Composites Reinforced with Spiral Polyethylene Terephthalate Fibers.}

\author{
${ }^{1}$ Paloma Fonseca Rodrigues, ${ }^{1}$ Tatiana Portela Ribeiro, ${ }^{2}$ Alex Neves Junior \\ ${ }^{1}$ Graduada em Engenharia Civil pela Universidade Federal de Mato Grosso, Campus Universitário do \\ Araguaia - Barra do Garças - MT \\ ${ }^{2}$ Professor Adjunto III no Departamento de Engenharia Civil e no Programa de Pós - Graduação em \\ Engenharia de Edificações e Ambiental - PPGEEA, Faculdade de Arquitetura, Engenharia e Tecnologia- \\ FAET, Universidade Federal de Mato Grosso- UFMT (alexnevesjr@gmail.com
}

RESUMO: Este trabalho apresenta um estudo sobre as propriedades mecânicas e de porosidade de compósitos reforçados com fibras de politereftalato de etileno (PET) espiraladas provenientes da reciclagem de garrafas de refrigerante. As fibras PET foram espiraladas com o objetivo de melhorar a zona de aderência entre a matriz e a fibra. A utilização de fibras em matrizes cimentícias tem por objetivo o controle de fissuração e microfissuração do material, aumentando a sua tenacidade. Foram confeccionados concretos utilizando o traço 1: 0,5: 0,5 e variando a relação água x cimento em 0,5 e 0,6 com a substituição parcial do cimento pela sílica ativa na proporção de $20 \%$ para o caso 0,6 , adicionando nos dois casos $1 \%$ de fibra em relação ao volume de concreto moldado para comparação com compósitos de referência sem fibras. Os resultados mostraram que todos os compósitos com a adição de fibras PET apresentaram resistência mecânica à compressão próxima àquelas sem fibras, e em relação ao ensaio de resistência à tração na flexão todos os compósitos fibrosos apresentaram melhoria no comportamento pósfissuração. Os compósitos fibrosos com relação água x cimento 0,6 apresentaram índices de absorção de água superiores aos compósitos de referência, devido aos vazios constatados na interface fibra - matriz e a presença da sílica ativa que alterou a sua reologia. O uso da relação água x cimento 0,5 nos compósitos fibrosos sem sílica ativa melhorou a sua reologia resultando em materiais com menores índices de absorção de água em relação às referências.

Palavras-chave: Sílica Ativa; Resistência à Compressão Simples; Resistência à Tração na Flexão; Absorção de Água por Capilaridade.

\begin{abstract}
This work presents a study about the mechanical and porosity properties of composites reinforced with spiraled polyethylene terephthalate (PET) fibers from the recycling of soda bottles. The PET fibers were spiraled in order to improve the properties of the interfacial transition zone between the matrix and the fiber. The use of fibers in cementitious matrix has the objective of controlling the cracking and microcracking of the material, increasing its tenacity. The composites were made using a composition of 1: 0.5 : 0.5 , varying the water $x$ cement ratio by 0.5 and 0.6 with the partial replacement of the cement by silica fume in the proportion of $20 \%$ for the case 0.6 . For the composites were added, in both cases, $1 \%$ of fiber in relation to the volume of molded concrete for comparison with reference composites without fibers. The results showed that all the composites with the addition of PET fibers showed compressive strength close to those without fibers, and in relation to the flexural tensile strength test, all the composites showed improvement in the post-cracking behavior. The fibrous composites with water to cement ratio 0.6 presented water absorption indexes higher than the reference composites due to the voids found in the interfacial transition zone and the presence of active silica that changed their rheology. The use of the water $x$ cement ratio 0.5 in the fibrous composites without active silica improved its rheology resulting in materials with lower water absorption indexes compared to the references.
\end{abstract}

Keywords: composites, silica fume, spiraled polyethylene terephthalate fibers, compressive strength, flexural tensile strength, water absorption by capillarity.

\section{INTRODUÇÃO}

O concreto, composto pela mistura de cimento Portland, água, agregado graúdo, agregado miúdo e eventualmente adições ou aditivos químicos é o material mais utilizado na construção civil atualmente. Há, no entanto, grande preocupação ambiental, 
uma vez que, a fabricação do cimento Portland emite grande quantidade de dióxido de carbono durante a calcinação do calcário e queima de combustíveis fósseis utilizados no processo de fabricação do clínquer (BAUER, 2011).

Dentro do contexto da sustentabilidade, o uso de rejeitos como a sílica ativa e de materiais alternativos como o PET na confecção de novos materiais constitui-se como alternativa interessante, levando-se em conta o fato de que o polietileno tereftalato (PET), por ser polimérico, é um material extremamente prejudicial à natureza quando descartado de forma incorreta, representando $20 \%$ do volume de lixo depositado nos aterros sanitários (SILVEIRA, 2014) e de que a sílica é um subproduto industrial da produção de sílico-metálico, ligas de ferro-silício ou outros produtos silicosos que devem ser reaproveitados de forma correta.

Atualmente o uso de fibras para reforço de matrizes cimentícias com o intuito de melhorar as características relacionadas aos esforços de tração em concretos tem sido frequente (MENESES, 2011; CORÓ, 2002; MARAGON, 2004). Dentre os tipos de fibras comumente utilizadas podemos citar: fibras poliméricas, fibras metálicas de aço, fibras vegetais e fibras minerais. Na matriz cimentícia, as fibras geram dois efeitos importantes a primeira de controlar a fissuração e microfissuração, conferindo ductilidade e melhorando a tenacidade (JOHNSTON 1994, apud SPECHT 2000). Foram encontrados diversos estudos de compósitos fibrosos com a utilização de fibras PET (MENESES, 2011; CORÓ, 2002; MARAGON, 2004), no entanto sua utilização foi feita em tiras lisas com diferentes comprimentos ou em pó, com resultados não satisfatórios.

A sílica ativa foi utilizada neste trabalho como material pozolânico com o intuito de melhorar a resistência e conferir menor permeabilidade ao concreto. Por ser um subproduto industrial e exercer um efeito físico (microfíler) e outro químico (pozolânico) durante o processo de hidratação do cimento, a sílica permite a obtenção de uma microestrutura mais densa, homogênea e uniforme, tornando viável seu emprego na composição de concretos que exigem elevada durabilidade. (SILVA FILHO, 1994; BENTZ \& STUTZMAN, 1994; ISAIA, 1995 apud HOFFMANN, 2001).

Assim, o objetivo deste trabalho é estudar o comportamento mecânico e de porosidade de matrizes de concreto com e sem substituição parcial de cimento por sílica ativa, reforçadas com fibras PET espiraladas, distribuídas aleatoriamente na matriz, a fim de promover o seu aproveitamento como reforço de materiais de construção à base de concreto de cimento Portland, promovendo, ao mesmo tempo, alternativas para diminuição deste passivo ambiental

\section{MATERIAL E MÉTODOS}

O cimento Portland utilizado foi do tipo CPII-Z-32 (Cimento Portland composto com pozolana) cuja resistência normatizada é de $32 \mathrm{MPa}$ aos 28 dias. Os tipos de agregados graúdos utilizados foram o seixo rolado, para os concretos com relação $\mathrm{a} / \mathrm{c}=0,6$ e a pedra britada para os concretos com relação a/c=0,5, ambos de granulometria variada. A areia utilizada foi do tipo média, lavada e peneirada em peneira ASTM 3,5 (abertura de 5,6 mm). A sílica ativa utilizada foi do fabricante Dow Corning Metais do Pará Ind. e Com. Ltda., tendo em sua composição a sílica amorfa (microssílica).

As fibras PET (densidade de $0,01 \mathrm{~g} / \mathrm{cm}^{3}$ ), obtidas de garrafas de refrigerante, foram utilizadas no formato espiralado, objetivando aumentar a área específica e promover maior aderência com a matriz do compósito, com comprimentos variando 
Rodrigues, P. F. Ribeiro, T. P. Neves Junior, A. Caracterização Mecânica de Compósitos Cimentícios Reforçados com Fibras de Politereftalato de Etileno Espiraladas. E\&S - Engineering and Science, (2017), 6:1.

entre 2 e 3,5cm. O volume de fibras, em gramas, a ser utilizado foi determinado segundo (BENTUR; MINDESS, 2006), pela equação abaixo:

$$
\mathrm{V}_{\text {fibras }}=\mathrm{V}_{\text {molde }} \cdot \mathrm{N}_{\text {moldes }}^{\mathrm{o}} \cdot \%_{\text {fibras }} \cdot 10^{6}
$$

Onde:

$\mathrm{V}_{\text {fibras }}=$ Volume das fibras, em $\mathrm{g}$

$\mathrm{V}_{\text {molde }}=$ Volume do molde, $\mathrm{em}^{3}$

$\mathrm{N}^{\mathrm{o}}$ moldes $=$ Número de moldes

$\%_{\text {fibras }}=$ Porcentagem de fibras

A água utilizada foi a fornecida pelo sistema de abastecimento de água da cidade de Barra do Garças-MT.

O traço utilizado neste trabalho teve os valores fixados na proporção $1: 0,5: 0,5$, com a relação água/material cimentício $(\mathrm{a} / \mathrm{mc})$ variando em 0,5 e 0,6 com $20 \%$ de substituição do cimento por sílica ativa nos compósitos com relação a/c=0,6. A porcentagem de fibras PET utilizadas na composição dos compósitos fibrosos foi de 1 $\%$ em relação ao volume de material confeccionado. Os compósitos sem fibras foram denominados de referência.

A Tabela 01 resume as características geométricas, o traço utilizado, as adições feitas e os ensaios realizados nos compósitos estudados.

Tabela 1: Características gerais dos compósitos estudado.

\begin{tabular}{c|c|c|c|c|c|c|c}
\hline $\begin{array}{c}\text { Corpo de } \\
\text { prova }\end{array}$ & $\begin{array}{c}\text { Ensaios } \\
\text { realizados }\end{array}$ & Formato & $\begin{array}{c}\text { Dimensões } \\
\text { (cm) }\end{array}$ & Traço & $\begin{array}{c}\text { Relação } \\
\mathbf{a} / \mathbf{c}\end{array}$ & \% Sílica & $\begin{array}{c}\text { \% fibras } \\
\text { PET }\end{array}$ \\
\hline $\begin{array}{c}\text { CPP`s sem } \\
\text { fibra }\end{array}$ & RTF & Prismático & $10 \times 10 \times 40$ & $1: 0,5: 0,5$ & 0,5 & 0 & 0 \\
\hline $\begin{array}{c}\text { CPP`s com } \\
\text { fibra }\end{array}$ & RTF & Prismático & $10 \times 10 \times 40$ & $1: 0,5: 0,5$ & 0,5 & 0 & 1 \\
\hline $\begin{array}{c}\text { CPC`s sem } \\
\text { fibra }\end{array}$ & AC e RCS & Cilíndrico & $10 \times 20$ & $1: 0,5: 0,5$ & 0,5 & 0 & 0 \\
\hline $\begin{array}{c}\text { CPC`s com } \\
\text { fibra }\end{array}$ & AC e RCS & Cilíndrico & $10 \times 20$ & $1: 0,5: 0,5$ & 0,5 & 0 & 1 \\
\hline $\begin{array}{c}\text { CPP`s sem } \\
\text { fibra }\end{array}$ & RTF & Prismático & $10 \times 10 \times 40$ & $1: 0,5: 0,5$ & 0,6 & 20 & 0 \\
\hline $\begin{array}{c}\text { CPP`s com } \\
\text { fibra }\end{array}$ & RTF & Prismático & $10 \times 10 \times 40$ & $1: 0,5: 0,5$ & 0,6 & 20 & 1 \\
\hline $\begin{array}{c}\text { CPC`s sem } \\
\text { fibra }\end{array}$ & AC e RCS & Cilíndrico & $10 \times 20$ & $1: 0,5: 0,5$ & 0,6 & 20 & 0 \\
\hline $\begin{array}{c}\text { CPC`s com } \\
\text { fibra }\end{array}$ & AC e RCS & Cilíndrico & $10 \times 20$ & $1: 0,5: 0,5$ & 0,6 & 20 & 1 \\
\hline
\end{tabular}

CPP: corpo de prova prismático; CPC: corpo de prova cilíndrico; AC: Absorção por capilaridade; RCS: Resistência à compressão simples; RTF: Resistência à tração na flexão

A moldagem dos corpos de prova cilíndricos e prismáticos, bem como os procedimentos de adensamento e cura obedeceram aos critérios da NBR 5738:1994.

Após a moldagem os corpos de prova foram imediatamente cobertos com material plástico transparente e panos úmidos, com a finalidade de evitar a perda de água do concreto. Os corpos de prova cilíndricos foram desmoldados após 24 horas e os prismáticos após 48 horas. A cura final até a realização dos ensaios foi feita em água saturada de cal hidratada. 
O ensaio de absorção de água por capilaridade obedeceu as prescrições da NBR 9779:1995e foram realizados na idade de 51 dias tanto para os corpos de prova com relação a/c=0,5 e 0,6 sendo calculado pela equação abaixo:

$$
\mathrm{C}=\frac{\mathrm{A}-\mathrm{B}}{\mathrm{S}}
$$

Sendo:

$\mathrm{C}=$ absorção da água por capilaridade $\left(\mathrm{g} / \mathrm{cm}^{3}\right)$;

$\mathrm{A}=$ massa do corpo de prova que permanece em que uma de suas superfícies permanece em contato com a lâmina d'água durante o tempo especificado $(\mathrm{g})$;

$\mathrm{B}=$ massa do corpo de prova seco a temperatura de $(23+-2)^{\circ} \mathrm{C}(\mathrm{g})$;

$\mathrm{S}=$ área da seção transversal $\left(\mathrm{cm}^{2}\right)$.

O ensaio de resistência à compressão simples foi realizado conformeNBR5739:1994para a idade de 51 dias nos corpos de prova com relação $\mathrm{a} / \mathrm{c}=0,5$ e 60 dias para os corpos de prova com relação $a / c=0,6$. A resistência à compressão foi calculada pela equação abaixo:

$$
\mathrm{fc}=\frac{4 * \mathrm{~F}}{\left(3,14 * \mathrm{D}^{2}\right)} / 100
$$

Onde:

$\mathrm{Fc}=$ Resistência à compressão, em MPa.

$\mathrm{F}=$ Força máxima em tf

$\mathrm{D}=$ Diâmetro da seção transversal em m

O ensaio de resistência a tração na flexão foi realizado conforme NBR 12142:1991, considerando a idade de 51 dias nos corpos de prova com relação a/c=0,5 e $\mathrm{a} / \mathrm{c}=0,6$.

A resistência à tração na flexão foi calculada conforme a equação abaixo:

$$
\mathrm{f}_{\mathrm{ctm}}=\frac{\mathrm{pl}}{\mathrm{bd}^{2}}
$$

Onde:

$\mathrm{f}_{\text {ctm }}=$ resistência à tração na flexão, em MPa;

$\mathrm{p}=$ carga máxima aplicada, em $\mathrm{N}$;

$1=$ distância entre cutelos de suporte, em mm;

$\mathrm{b}=$ largura média do corpo de prova na seção de ruptura, em mm;

$\mathrm{d}=$ altura média do corpo de prova, na seção de ruptura, em mm.

A Tenacidade é definida como uma medida da quantidade de energia que um material pode absorver antes de fraturar e pode ser calculada através da área num gráfico tensão x deformação do material, portanto foi calculada nesta pesquisa integrando a curva obtida no ensaio de tração na flexão do material. 
Rodrigues, P. F. Ribeiro, T. P. Neves Junior, A. Caracterização Mecânica de Compósitos Cimentícios Reforçados com Fibras de Politereftalato de Etileno Espiraladas. E\&S - Engineering and Science, (2017), 6:1.

\section{RESULTADOS E DISCUSSÕES}

As Figuras 01 e 02 mostram os resultados obtidos para o ensaio de absorção de água por capilaridade para os compósitos com relação a/c=0,5 e 0,6 respectivamente.

Figura 01 - Resultados do ensaio de absorção por capilaridade para os concretos com relação $\mathrm{a} / \mathrm{c}=0,5$

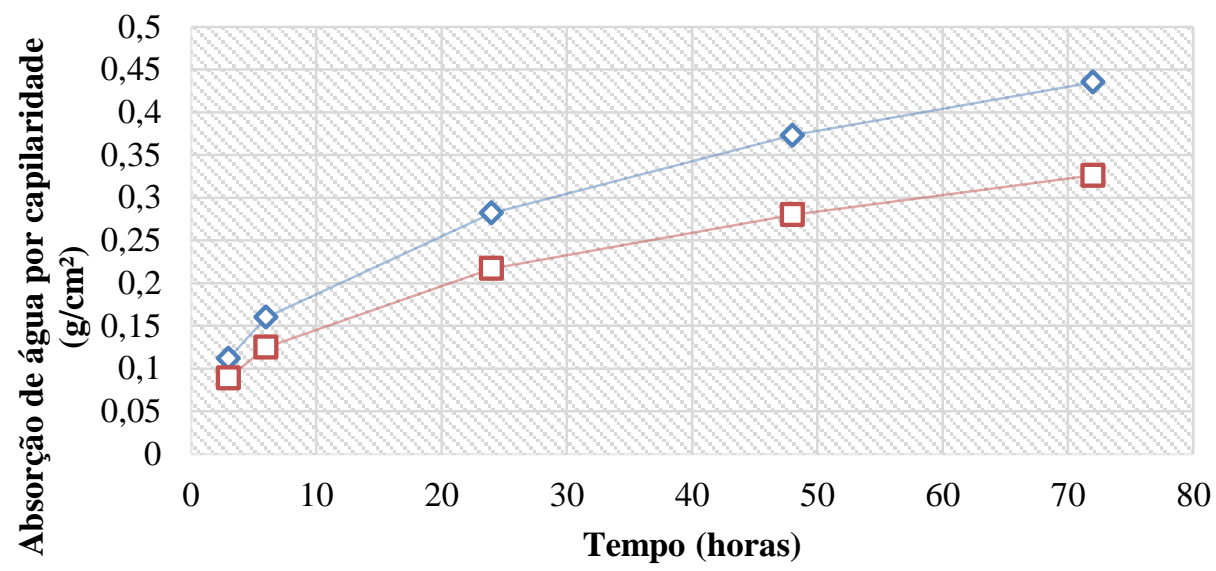

$\diamond$ Absorção de água por capilaridade $-\square-$ Absorção de água por capilaridade

Verifica-se pela Figura 01 que os corpos de provas sem adição das fibras apresentaram maiores valores de absorção de água em todos os tempos analisados. Nestes compósitos as fibras ficaram totalmente imersas na matriz, não existindo vazios na superfície para percolação de umidade. Além disso, a elevada trabalhabilidade da matriz favoreceu o preenchimento do interior das fibras espiraladas pela argamassa, diminuindo a formação de vazios.

Figura 2 - Resultados do ensaio de absorção por capilaridade para os concretos com relação $\mathrm{a} / \mathrm{c}=0,6$

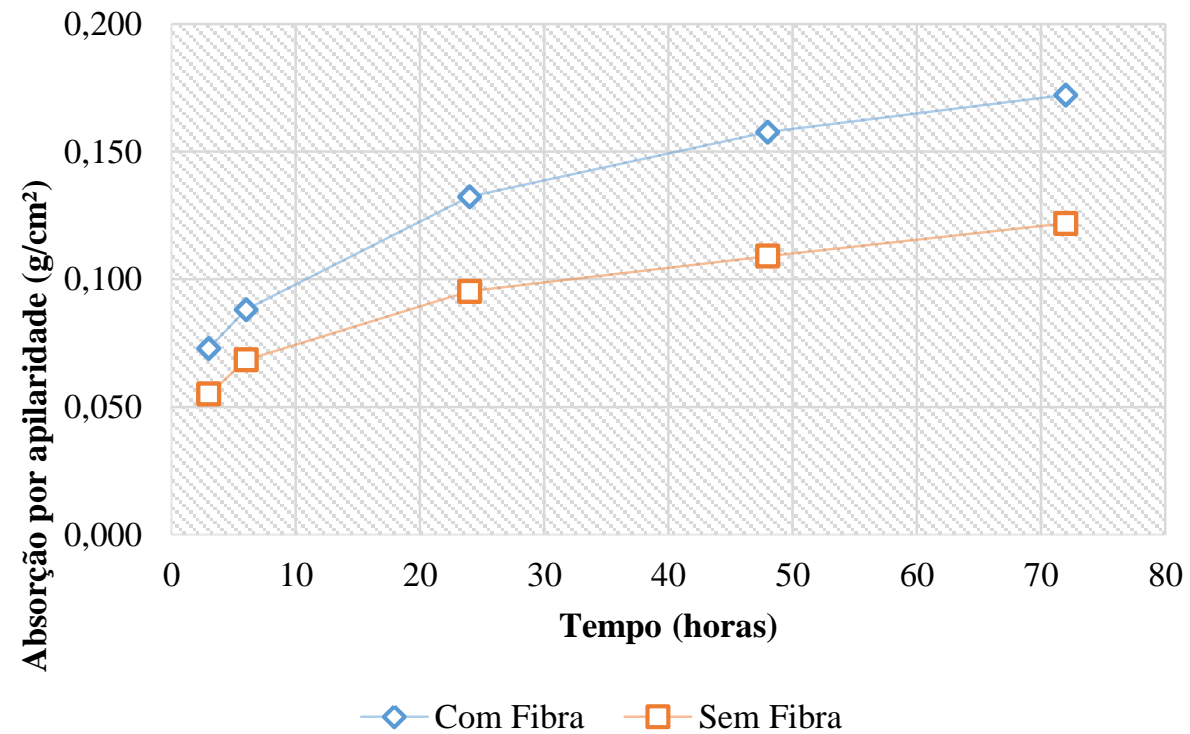

Verifica-se pela Figura 02 que os concretos com adição de fibras PET absorveram cerca de $0,017 \mathrm{~g} / \mathrm{cm}^{2}$ a mais de água quando comparados àqueles sem fibras. A presença 
Rodrigues, P. F. Ribeiro, T. P. Neves Junior, A. Caracterização Mecânica de Compósitos Cimentícios Reforçados com Fibras de Politereftalato de Etileno Espiraladas. E\&S - Engineering and Science, (2017), 6:1.

da sílica, para uma mesma quantidade de água adicionada, alterou a reologia da matriz comprometendo o preenchimento do interior das fibras pela argamassa. Em função disso, parte das fibras ficaram expostas nos corpos de prova o que alterou os resultados.

As Tabelas 02 e 03 mostram resultados obtidos para o ensaio de resistência à compressão simples para os compósitos com relação a/c=0,5 e 0,6 respectivamente.

Tabela 02- Valores da resistência à compressão dos concretos com relação a/c=0,5

\begin{tabular}{c|c}
\hline \multicolumn{2}{c}{ Resistência à compressão Média (MPa) } \\
\hline Com Fibra & 12,63 \\
\hline Sem Fibra & 11,18 \\
\hline
\end{tabular}

Verifica-se pela Tabela 02 que, de acordo com os resultados, a resistência à compressão dos corpos de prova com adição de fibras de garrafas PET é 13,84\% maior que a dos corpos de prova sem adição de PET. Porém, ao considerarmos o coeficiente de variação, 1,60\% para os corpos de prova sem PET e 6,51 para os corpos de prova com PET, verificamos que as resistências foram estatisticamente iguais.

$\mathrm{O}$ aumento da resistência à compressão simples se deve, aparentemente, ao efeito de confinamento gerado pelas fibras sobre a matriz.

Tabela 03- Valores da resistência à compressão dos concretos com relação a/c=0,6.

\begin{tabular}{c|c}
\hline \multicolumn{2}{c}{ Resistência à compressão Média $(\mathrm{MPa})$} \\
\hline Com Fibra & 19,043 \\
\hline Sem Fibra & 18,857 \\
\hline
\end{tabular}

Verifica-se pela Tabela 03 que estatisticamente a resistência à compressão simples dos corpos de prova com e sem fibras obtiveram valores próximos, pois, apesar da presença das fibras mostrarem uma tendência ao aumento da resistência em razão do efeito de confinamento do material, os possíveis vazios na interface fibra matriz, que explicaram os resultados obtidos no ensaio de absorção de água por capilaridade, impediram que a resistência à compressão dos concretos com fibras alcançassem maiores valores.

As Tabelas 04 e 05 mostram os resultados obtidos para o ensaio de resistência à tração na flexão para os compósitos com relação a/c=0,5 e 0,6 respectivamente.

Tabela 04- Força e resistência à tração média dos concretos com relação $a / c=0,5$

\begin{tabular}{c|c|c}
\hline & Força Média (N) & fctm (MPa) \\
\hline Sem Fibra & 4400 & 1,057 \\
\hline Com Fibra & 5890 & 1,413 \\
\hline
\end{tabular}

Verifica-se pela Tabela 04 que o valor da tensão máxima de tração na flexão dos corpos de prova com adição de fibras PET foi 33,68\% maior que a dos corpos de prova sem adição de PET. Na fase de pré fissuração, o comportamento dos dois compósitos é próximo, pois neste estágio a resistência é de responsabilidade da matriz. Após a força de ruptura máxima, as fibras são mobilizadas ocorrendo um ganho de resistência póspico nos concretos com fibras. Os compósitos fibrosos apresentaram um aumento de tenacidade de aproximadamente $297,35 \%$.

Tabela 05- Força e resistência à tração média dos concretos com relação a/c=0,6

\begin{tabular}{c|c|c}
\hline & Força Média (N) & fctm (Mpa) \\
\hline Sem Fibra & 3115 & 0,7476 \\
\hline Com Fibra & 3065 & 0,7356 \\
\hline
\end{tabular}


Verifica-se pela Tabela 05, através do valor máximo obtido para a resistência à tração, que os concretos com adição de fibras PET alcançaram valores um pouco menores, mas estatisticamente iguais em relação ao concreto sem fibras, isso ocorre em função da possível porosidade existente na interface fibra matriz nestes concretos. Para estes compósitos, aqueles reforçados com fibras apresentaram um aumento de tenacidade de $91 \%$ em relação aos concretos com fibras.

As Figuras 03 e 04 mostram os gráficos típicos de tensão x deformação, para os compósitos estudados sem e com o uso do reforço das fibras PET, respectivamente.

Figura 03 - Curva tensão x deformação típica para os concretos sem reforço das fibras PET.

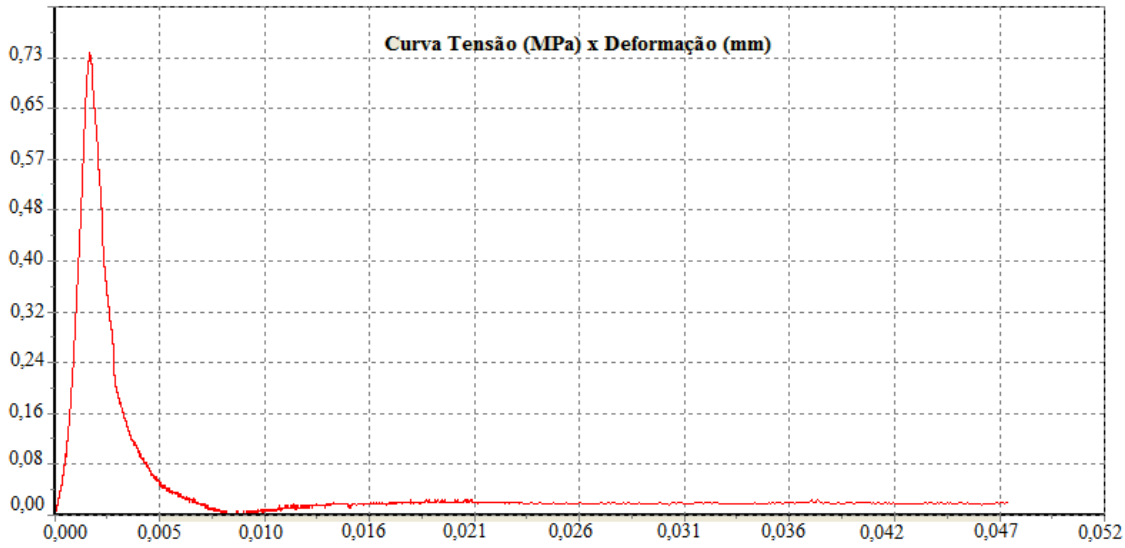

Verifica-se pela Figura 03 que ao atingir a resistência de pico o material rompe-se abruptamente, evidenciando o comportamento típico de um material frágil e com baixa tenacidade.

Figura 04 - Curva tensão x deformação típica para os concretos reforçados com fibras PET.

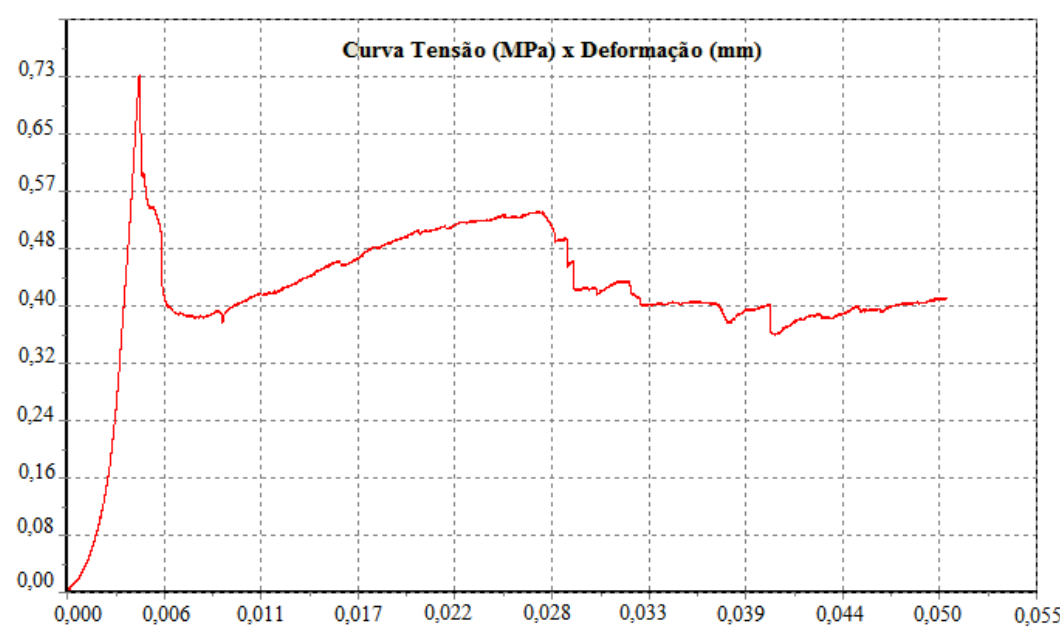

Verifica-se pela Figura 04 que após atingir a resistência de pico o material continua admitindo deformações conforme a intensidade do carregamento aumenta, evidenciando a elevada tenacidade e o comportamento dúctil proporcionado pela adição de fibras à matriz.

\section{CONCLUSÕES}

Para os compósitos com relação a/c=0,5, os índices de absorção de água por capilaridade foram maiores para os compósitos sem o reforço das fibras, indicando o 
favorável efeito de confinamento gerado pelo reforço, colaborado também pelo aumento da eficiência de aderência alcançada pela matriz através do envolvimento da argamassa na fibra. Nos compósitos com relação a/c=0,6, o comportamento observado foi contrário, onde no caso dos compósitos reforçados, os índices de absorção de água foram maiores que nos compósitos sem reforço, isso ocorreu devido, à má reologia da matriz, causada pela insuficiente quantidade de água para hidratação da sílica ativa adicionada, que comprometeu o envolvimento da argamassa na fibra, gerando vazios e induzindo a uma maior absorção.

Para os compósitos com relação a/c=0,5 e 0,6 quanto aos resultados de resistência à compressão simples, verifica-se que os valores foram estatisticamente iguais, demonstrando que para esse tipo de esforço, o reforço com as fibras não trouxe melhora significativa na performance mecânica.

Para os compósitos com relação a/c=0,5 e 0,6 quanto aos resultados de resistência à tração na flexão, é nítido o ganho de tenacidade apresentado pelo material pela presença do reforço, com um ganho substancial de resistência pós fissuração. Nas duas matrizes estudadas observa-se que apesar do aumento da tenacidade, a tensão máxima de ruptura dos compósitos com e sem fibras foi estatisticamente o mesmo, já que neste estágio a resistência é determinada apenas pela matriz sem a participação do reforço.

Logo, o uso das fibras PET como reforço de matrizes cimentícias encontra elevado potencial de utilização em aplicações que prezem por um controle mais rigoroso de fissuração, como pisos de elevada trafegabilidade, calçadas, elementos estruturais como lajes, vigas e pilares sob elevada solicitação.

\section{REFERÊNCIAS}

BAUER, L. A. Falcão. Materiais de construção, 1. 5.ed. revisada, [reimp.]. Rio de Janeiro: LTC, 2011. 471 p.

BENTUR, A.; MINDESS, S. Fibre Reinforced Cimentitious Composites, 2.ed. Oxon: CRC Press, 2006. 624 p.

BENTZ, D. P.; STUTZMAN, P. E. Evolution of porosity and calcium hydroxide in laboratory concretes containing sílica fume. Cementand Concrete Research, V. 24, no. 6, p. 1044-1050, 1994.

BRASIL. ASSOCIAÇÃO BRASILEIRA DE NORMAS TÉCNICAS (ABNT). NBR 9779: Argamassa e Concreto Endurecidos - Determinação de Absorção de Água por capilaridade. Rio de Janeiro, abr. 1995. 2p.

BRASIL. ASSOCIAÇÃO BRASILEIRA DE NORMAS TÉCNICAS (ABNT). NBR 12142: Concreto - Determinação da Resistência à Tração na Flexão de Corpos de Prova Prismáticos. Rio de Janeiro, dez. 1991. 3p.

BRASIL. ASSOCIAÇÃO BRASILEIRA DE NORMAS TÉCNICAS (ABNT). NBR 5739: Concreto - Ensaio de Compressão de Corpos de Prova Cilíndricos. Rio de Janeiro, jul. 1994. 4p.

BRASIL. ASSOCIAÇÃO BRASILEIRA DE NORMAS TÉCNICAS (ABNT). NBR 5738: Concreto - Procedimento para Moldagem e Cura dos Corpos de Prova. Rio de Janeiro, dez. 2003. 6p. 
CORÓ, A. G. Investigação das Propriedades Mecânicas de Concretos Reforçados com Fibras PET. 2002. 46 f. Monografia (Especialização em Engenharia Civil) Universidade Regional do Noroeste do Estado do Rio Grande do Sul. Ijuí, 2002.

HOFFMANN, A. Ti. Influência da Adição de Sílica Ativa, Relação Água/Aglomerante, Temperatura e Tempo de Cura no Coeficiente de Difusão de Cloretos em Concretos. 2001. 132 f. Dissertação (Mestrado em Engenharia) Universidade Federal do Rio Grande do Sul, Pós-Graduação em Engenharia Civil, Porto Alegre, 2001.

MARANGON, Ei. Aspectos do Comportamento e da Degradação de Matrizes de Concreto de Cimento Portland Reforçados com Fibras Provenientes da Reciclagem de Garrafa PET. 2004. 75 f. Trabalho de Conclusão do Curso (Especialização em Engenharia Civil) - Universidade Regional do Noroeste do Estado do Rio Grande do Sul. Ijuí, 2004.

MENESES, I. A. Avaliação de Concreto com Adição de Fibras PET Submetido a Altas Temperaturas. 2011. 86 f. Dissertação (Mestrado em Engenharia Civil) Universidade Federal do Rio Grande do Norte, Pós-Graduação em Engenharia Civil, Natal, 2011.

SILVA FILHO, L. C. P. Durabilidade do concreto à ação de sulfatos: análise do efeito da permeação de água e da adição de microssílica. 1994. 143 p. Dissertação (Mestrado em Engenharia) - Universidade Federal do Rio Grande do Sul, Curso de Pósgraduação em Engenharia Civil, Porto Alegre.

SILVEIRA, A. Vantagens da reciclagem. Disponível em: www.vassourapet.com.br. Acesso em: Outubro, 2014.

SPECHT, L. P. Comportamento de Misturas Solo-Cimento_fibra Submetidas a Carregamentos Estáticos e Dinâmicos Visando a Pavimentação. 2000. $94 \mathrm{f}$. Dissertação (Mestrado em Engenharia) - Universidade Federal do Rio Grande do Sul, Programa de Pós-Graduação em Engenharia Civil, Porto Alegre, 2000. 